NBER WORKING PAPER SERIES

\title{
THE EFFECTS OF HEALTH ON HEALTH INSURANCE STATUS IN FRAGILE FAMILIES
}

\author{
Hope Corman \\ Anne Carroll \\ Kelly Noonan \\ Nancy E. Reichman \\ Working Paper 12197 \\ http://www.nber.org/papers/w12197
NATIONAL BUREAU OF ECONOMIC RESEARCH 1050 Massachusetts Avenue Cambridge, MA 02138
April 2006

This research was supported by Grants \#R01-HD-45630 and \#R01-HD-35301 from the National Institute of Child Health and Human Development. We are grateful for helpful comments from Bisakha Sen, Steven Nock, and Alan Monheit and for assistance from Maria Fontana, Magdalena Ostatkiewicz, and Ofira Schwarz-Soicher. The views expressed herein are those of the author(s) and do not necessarily reflect the views of the National Bureau of Economic Research.

(C)2006 by Hope Corman, Anne Carroll, Kelly Noonan and Nancy E. Reichman. All rights reserved. Short sections of text, not to exceed two paragraphs, may be quoted without explicit permission provided that full credit, including (C) notice, is given to the source. 
The Effects of Health on Health Insurance Status in Fragile Families Hope Corman, Anne Carroll, Kelly Noonan and Nancy E. Reichman NBER Working Paper No. 12197

April 2006

JEL No. I1, I3

\begin{abstract}
We use data from the Fragile Families and Child Wellbeing study to estimate the effects of poor infant health, pre-pregnancy health conditions of the mother, and the father's health status on health insurance status of urban, mostly unmarried, mothers and their one-year-old children. Virtually all births were covered by health insurance, but one year later about one third of mothers and over 10 percent of children were uninsured. We separately examine births that were covered by public insurance and those that were covered by private insurance. The child's health status had no effect, for the most part, on whether the mother or child became uninsured. For publicly insured births, a maternal physical health condition made it less likely that both the mother and child became uninsured, while maternal mental illness made it more likely that both the mother and child lost insurance coverage. For privately insured births, the father's suboptimal physical health made it more likely that the mother, but not the child, became uninsured.
\end{abstract}

\section{Hope Corman \\ Department of Economics \\ Rider University \\ Lawrenceville, NJ 08648-3099 \\ and NBER \\ corman@rider.edu}

Anne Carroll

Rider University

2083 Lawrenceville Road

Lawrenceville, NJ 08648

carroll@ rider.edu

\author{
Kelly Noonan \\ Rider University \\ 2083 Lawrenceville Road \\ Lawrenceville, NJ 08648 \\ and NBER \\ knoonan@rider.edu \\ Nancy E. Reichman \\ University of Medicine and Dentistry of New \\ Jersey \\ 97 Paterson Street, Room 435 \\ New Brunswick, NJ 08903 \\ reichmne@umdnj.edu
}




\section{Introduction}

Most women in the U.S. have health insurance when they give birth. In the recent Fragile Families and Child Wellbeing birth cohort survey of urban (mostly unmarried) parents, only 1 percent of births were not covered by public or private health insurance. One year later, however, about 12 percent of the focal children and approximately 29 percent of the mothers were uninsured.

A large literature indicates that people with health insurance have better access to care, are more likely to get needed care, and have better health outcomes than those without insurance (e.g. Hadley 2002; Kasper et al. 2002; Ayanian et al. 2000; Newacheck et al. 1998; Currie and Gruber 1996; Busch and Duchovny 2005; Olson, Tang and Newacheck 2005; Aiken et al. 2004; Levy and Meltzer 2001). Within families, individuals' health insurance status and utilization of health care are often interdependent. For example, expanded Medicaid coverage for mothers increases the likelihood that their children are enrolled in Medicaid (Dubay and Kenney 2003; Aizer \& Grogger 2003) and there is evidence that a mother's utilization of health care affects utilization of pediatric care, regardless of insurance status (Hanson 1998).

Conversely, health can affect insurance status, though the direction is ambiguous and the mechanism depends on whether the insurance is obtained from private or public sources. For private insurance, most individuals face at least some portion of the costs of coverage directly, either because they pay for the coverage themselves in the individual insurance market or because they experience a wage reduction when coverage is obtained through an employer. The extent of cost-sharing by the employer will determine whether an individual considers having the insurance a net benefit and whether he or she decides to purchase the insurance (when given the option). Individuals in poor health (or who have family members in poor health) may be more 
likely than those in good health (or with healthy families) to purchase insurance to offset their expected health care expenses. However, if premiums are correlated with individuals' (or families') health risk, individuals (or families) in poor health may be less inclined to obtain insurance or to maintain insured status since their premiums will be high relative to their income. On the other hand, if premiums are community rated, individuals (or families) in poor health may be more likely than those in good health to obtain insurance because premiums will be low relative to their risk and income (Bundorf, Herring, and Pauly 2005). Further complicating the situation is that health can affect employment status or even the choice of employer.

The expected direction of the effect of poor health of family members on mothers' and children's public health insurance status is also ambiguous. A severe health problem of the mother may result in disability, which may make her eligible for Medicaid. Poor health of a family member may cause a parent to lose employment or confront large medical expenses, perhaps pushing household income low enough for a mother and her children to qualify for public health insurance, or it may motivate low-income parents to seek or maintain public insurance for that individual or other family members. Alternatively, poor health of any family member may make it logistically difficult for a low-income mother to apply for or maintain public health insurance for herself or her children. ${ }^{1}$

For individuals (or families) in poor health, the expected benefits of having insurancepublic or private-may also depend on the specific types of health problems involved. For example, conditions that require ongoing treatment may provide more of an incentive to being

\footnotetext{
${ }^{1}$ In previous research using the Fragile Families and Child Wellbeing data, we found that having an unhealthy infant increased the probability that the parents were not living together (Reichman, Corman, and Noonan 2004), decreased the probability that both the mother (Corman, Noonan, and Reichman 2005) and father (Noonan, Reichman, and Corman 2005) were employed, and increased the probability that the mother received welfare (Reichman, Corman, and Noonan forthcoming) 12-18 months after the birth. For reasons discussed above, these consequences could translate into positive or negative effects on health insurance of the mothers and children.
} 
insured than those that are not managed as closely. Also, conditions that are more likely to be covered (or covered more fully) by insurance (e.g., asthma, cardiac problems) may provide more of an incentive to being insured than those for which health insurance benefits tend to be less generous (e.g., mental illness).

In this study, we use longitudinal data from the Fragile Families and Child Wellbeing study to estimate the effects of poor infant health, pre-pregnancy health conditions of the mother, and the father's health status on health insurance status of urban, mostly unmarried, mothers and their one-year-old children. We examine why a good share of mothers and children in this vulnerable population become uninsured so soon after an insured birth, focusing on the effects of child, maternal, and paternal health. We separately examine mothers who had public insurance and those who had private insurance at the time of the birth. The results provide important information about how health affects health insurance_-an important family resource, particularly for those with little financial buffer.

\section{Background}

\section{Sociodemographic correlates of health insurance status}

Much previous research has identified sociodemographic correlates of health insurance status. Some studies have considered any type of insurance, while others have focused on public or private insurance. We review this literature below, first focusing on studies of health insurance generally and then focusing on studies of public or private insurance status. The review is by no means exhaustive. Rather, we highlight recent studies that are particularly relevant to our study. 


\section{$\underline{\text { Any health insurance }}$}

Schoen and DesRoches (2000), in a review of results from three different surveys about adult insurance coverage ${ }^{2}$, found that low income increases the likelihood of being uninsured and that the uninsured are disproportionately African American, Hispanic, and unmarried. Holahan, Dubay, and Kenney (2003) examined insurance coverage of children using the 2000 Current Population Survey. Like Schoen and DesRoches, they found that children in low-income households are more likely than those in higher-income households to lack insurance coverage and that Hispanic children are much less likely than non-Hispanic children to have coverage. They also found that children whose parents are not employed or are non-native non-citizens are disproportionately uninsured.

The above studies are valuable because they provide snapshots of typically uninsured adults and children. However, to better understand the mechanisms underlying insurance status it is useful to examine changes in individuals' health insurance status over time. Moreover, because public insurance coverage is linked primarily to eligibility while private insurance coverage is linked primarily to employment status, we expect that the factors affecting insurance loss among mothers and their young children differ by whether the mother had public or private insurance at the time of her child's birth. For example, increased income could lead to loss of eligibility for public health insurance and increase the likelihood of becoming uninsured. On the other hand, increased income may result from a shift from part-time to full-time employment and decrease the likelihood of being uninsured. Studies that pool together individuals with both types of coverage at an initial period may lose important information concerning what causes

\footnotetext{
${ }^{2}$ RWJ Foundation 1996-1997 Community Tracking Survey, 1995-1997 Kaiser Commonwealth State Low Income Surveys, and the Kaiser Commonwealth 1997 National Survey of Health Insurance.
} 
insurance loss. Below we review studies that examine changes in insurance status among individuals with public or private insurance.

\section{$\underline{\text { Public Insurance }}$}

A handful of studies, all using cross-sectional data, have identified correlates of insurance loss for individuals who at one point in time received public health insurance. Sommers (2005), using data from the 2001-2004 Current Population Surveys, found that publicly insured children who are older, are Latino, and do not have other family members enrolled in public insurance are more likely than their counterparts without these characteristics to become uninsured. Aiken, Freed, and Davis (2004), using 1999 National Survey of America's Families (NSAF) data, found that children with a guardian (usually the mother) who is not married are more likely than those with married parents to lose public insurance coverage and also that children who are Hispanic are much more likely than non-Hispanic children to lose public health insurance. Haley and Kenney (2003), using NSAF data from 1997 and 1999, examined health insurance loss among Medicaid-eligible children and found that those who are Hispanic or have parents with low levels of education are more likely than children who are non-Hispanic or have more educated parents to experience a spell of being uninsured.

Spillman (2000), using data from the 1997 NSAF, found that adults who are very poor (have household incomes below the poverty line) and unmarried parents are more likely to have gaps in insurance coverage than higher-income adults and married parents. Additionally, she found that adults living in households with no full-time workers are more likely than adults living in households with employed adults to have gaps in insurance. These associations were not examined in a multivariate context. 


\section{$\underline{\text { Private Insurance }}$}

Kasper et al. (2000), using 1995-1997 data from the Kaiser Survey of Family Health Experiences, found that among individuals with private health insurance, those who have low incomes are disproportionately represented among those who lose insurance coverage. Baker et al. (2002), examining data from late-middle age respondents to the Health and Retirement Survey (1992-1994), found that individuals who lose private coverage are more likely to be female, nonwhite, unmarried, poor, and less educated than those who maintain coverage.

\section{$\underline{\text { Overview }}$}

Studies have found that ethnicity, race, immigration status, education, income, and family structure are all strongly related to health insurance status. Hispanics are less likely than nonHispanics to have both public and private insurance, possibly due to immigration status or language barriers. The associations for blacks, however, are much less consistent across studies. Not surprisingly, one of the strongest negative predictors of public insurance coverage is immigrant status. Low education is associated with a reduced likelihood of having or maintaining either type of insurance. Unmarried women are less likely to have private health insurance and more likely to have public insurance than married women.

\section{Effects of Health Status on Health Insurance Status}

\section{Children}

Sommers (2005) found that children in good health are more likely than those with poor health to drop out of Medicaid or the State Children's Health Insurance program (SCHIP) and to become uninsured. Similarly, Haley and Kenney (2003) found that Medicaid-eligible children with functional limitations are less likely than those without limitations to experience a gap in insurance coverage. However, they found that the parent's self-report of the child's overall 
health status was not associated with the child's insurance loss. Shenkman et al. (2002) using data for all children enrolled in Florida's Healthy Kids program during a one-month period, found that children with at least one special health care need and those with a mental health diagnosis were less likely than physically and mentally healthy children to disenroll from the state's SCHIP program. The results from these three studies are consistent in that they find that low-income children in poor health are more likely than those in good health to maintain insured status. In contrast, however, Miller et al. (2005) found that children who disenrolled from the SCHIP program in New Jersey and became uninsured were more likely than those who remained enrolled to be in fair or poor health.

Studies that have focused on populations of children, rather than insured children, have found positive associations between poor child health and insurance gaps or lack of insurance. Olson et al. (2005), using data from the National Health Interview Survey (2000- 2001), compared children that spent part of a year uninsured to those who were continuously insured (either public or private) and found that children with insurance gaps were more likely to be in fair or poor health. Aiken et al. (2004) found that continuously uninsured children were more likely than those with at least sporadic health insurance coverage to be in fair or poor health. Finally, Satchell and Pati (2005), who examined a sample of vulnerable children (with chronic health conditions, racial/ethnic minorities, or living in poverty), found no significant differences in the proportions of healthy and unhealthy children that experienced health insurance gaps. $\underline{\text { Adults }}$

Fewer studies have examined the effects of adult's health on health insurance status. Most have focused on private insurance. One exception is a study by Spillman (2000), discussed earlier, which found that adults in fair or poor health are more likely than those in good health to 
have gaps in public health insurance. This result, in conjunction with the studies of children discussed above, suggests that the effects of poor health on insurance loss among those with public insurance may be different for children and adults.

Bundorf, Herring, and Pauly (2005) found a positive relationship between health risk and coverage for those in the private insurance market in their analysis of 1996-2002 Medical Expenditure Panel Survey data. Blumberg and Nichols (2001), using the 1997 National Health Interview Survey to analyze the characteristics of workers who decline employers' offers of health insurance to become uninsured, and found that these workers were in poorer mental health than those who took up employer coverage. Their results for physical health measures were mixed-those who declined coverage had worse self-reported health and were more likely to report having asthma or migraines, but were less likely to report diabetes. Kasper, et al. (2000), who examined both children and adults, found that individuals with health conditions requiring frequent medical care are disproportionately represented among those who lose coverage. Schoen and DesRoches (2000) found that individuals who lose coverage for a relatively brief period are just as likely as those who were continuously insured to be in fair or poor health. Likewise, Baker et al. (2002) found no differences in self-reported health status between adults that maintained private health insurance coverage and those who lost private health insurance. These results suggest that the effect of health status on loss of private coverage may vary by type of health condition.

\section{Overview}

Previous research on the effects of health on health insurance status suggests that there are different effects for individuals with private and public insurance and that there may be different effects for adults and children. With the exception of Satchel and Pati (2005) and 
Shenkman et al. (2002), all the above studies used self-reported measures of health. There is evidence that individuals tend to under-report their health conditions (e.g. Goldman et al. 2003; Zhu et al. 1999), including cancer history (Desai et al. 2001). If the degree of underreporting is consistent across different conditions, it may not be that problematic. However, studies have found that the extent of underreporting varies by condition, ${ }^{3}$ which introduces measurement error that makes it difficult to compare results across studies. Finally, none of the studies included health measures for family members other than the focal person. Such an omission ignores the interdependency of family members, which is particularly important for children since adults make decisions on their behalf. For example, the ability of a mother to obtain and maintain health coverage for her child may be a function of her own physical and mental health. The child's health may also affect the mother's insurance status—particularly when public insurance is involved, as there may be economies of scale in the enrollment process.

\section{Our contribution}

In this study, we estimate the probability of health insurance loss among a populationbased sample of mothers and their one-year-old children. We examine the effects of the child's health endowment, the mother's health status, and the father's health status on the probability of insurance loss for both the mother and the child. We conduct separate analyses for mothers who were covered by public and private insurance at the time of the birth. The health status measures are drawn primarily from medical records, reducing the potential for measurement error that may accompany self-reported measures. Loss of insurance is modeled as a function of the child's health at birth, the mother's pre-pregnancy physical and mental health, the father's physical and

\footnotetext{
${ }^{3}$ For example, Goldman et al. found that the underreporting of hypertension is considerable (nearly half of those that have the condition do not report it), while the underreporting of diabetes is less substantial, and Zhu et al. found varying degrees of discrepancies when comparing self-reported data to medical records for men who were asked about different conditions related to the urogenital tract.
} 
mental health at the time of the birth, socioeconomic characteristics of the mother and the father, the relationship status and living arrangement of the parents, and neighborhood-level poverty. We also include state fixed effects to control for insurance markets, labor markets, and policy environments.

As indicated earlier, health problems could either increase or decrease the likelihood of loss of insurance for mothers and their children. If they decrease the probability of health insurance loss, it would provide evidence that the public safety net system is working. If they increase the probability of insurance loss, it would point to needed public policy changes, as coverage disruptions can result in the loss or delay of necessary care that in turn could lead to unnecessary illness, hospitalization, or even death. The costs associated with these adverse events may exacerbate financial hardship, trapping families in poverty and reducing their chances of upward mobility.

\section{Data}

We use data from a recent national birth cohort survey that have been linked to medical records of mother respondents and their babies. The Fragile Families and Child Wellbeing (FFCWB) survey follows a cohort of parents and their newborn children in 20 large U.S. cities (in 15 states). The study was designed to provide information about the conditions and capabilities of new (mostly unwed) parents; the nature, determinants, and trajectories of their relationships; and the long-term consequences for parents and children of welfare reform and other policies. The survey data are rich in sociodemographic characteristics of both mothers and fathers, and include information on parents' relationships and living arrangements. 
The FFCWB study randomly sampled births in 75 hospitals between 1998 and 2000. By design, approximately three quarters of the interviewed mothers were unmarried. Face-to-face interviews were conducted with 4898 mothers while they were still in the hospital after giving birth. The infants' fathers were also interviewed, shortly thereafter in the hospital or at another location. Baseline response rates were 86 percent among eligible mothers and 78 percent among eligible fathers (fathers were eligible if the infant's mother completed an interview). Additional data have been collected from the hospital medical records (from the birth) for a sub-sample of 2994 births in 17 cities (in 13 states). ${ }^{4}$ Measures of census tract-level poverty were linked to the data using the mothers' baseline addresses. Follow-up interviews were conducted over the telephone with mothers when the child was one year old; 89 percent of the mothers who completed baseline interviews were re-interviewed when their children were between 12 and 18 months old.

The enhanced Fragile Families data are well suited for analyzing the effects of child, maternal, and paternal health on insurance loss of mothers and children because they represent a population that is vulnerable to experiencing lapses in health insurance (about two-thirds of the births were covered by public insurance), were collected as part of a longitudinal birth cohort study, and include: (1) detailed data on the child's health from birth; (2) detailed data on the mother's pre-pregnancy physical and mental health; (3) data on the father's physical and mental health; (4) information about insurance status at the time of the birth and at the time of the one year follow-up interview; (5) measures of socioeconomic status (e.g., education, neighborhood poverty) of both mothers and fathers; (6) data on the fathers regardless of whether they lived

\footnotetext{
${ }^{4}$ The medical record data collection is ongoing. The chronological order of the data collection reflects administrative procedures for obtaining approval at the different hospitals rather than decisions on the part of individual respondents to have their records reviewed.
} 
with their children; and (7) detailed information on the parents' relationship status, living arrangements, and other children (together and with other partners) at the time of the birth.

\section{Descriptive Analysis}

Below we describe the measures we use in our analyses, present summary statistics, and point out many salient characteristics of the sample. Unless indicated otherwise, all covariates are measured at baseline. In general, we use mother reports for information about the mother and father reports for information about the father. However, in cases where father data are missing, we use mother reports about the father if these are available. We restrict the sample to 2,400 nonmultiple births that were covered by health insurance for which there were no missing data on any of the main analysis variables from the mother's baseline and one year follow-up surveys, medical records, and address files.

\section{Health insurance}

Health insurance status and type of insurance, of the mother as well as the child, were reported by the mother at both the baseline and follow-up interviews. A small number of mothers (39) were excluded from the analyses because they did not have health insurance at baseline. The handful of births that were reportedly covered by both public and private health insurance (8) are included in both the analyses of publicly insured births and the analyses of privately insured births.

Table 1 shows a strong association between the insurance coverage of mothers and that of their children. Of the 705 mothers who lost insurance, 260 (37\%) of their children also lost coverage. Of the 1,695 mothers who had insurance both at birth and one year later, 1,658 (98\%) of their children had coverage at both of these time points. 
Characteristics of the sample by mothers' baseline health insurance type (public or private) are presented in Table $2 .{ }^{5}$ Over one third (37\%) of mothers who were covered by public insurance at baseline were uninsured at the time of the follow-up interview, as were 15 percent of their children. In contrast, 14 percent of the mothers with private insurance at the time of the birth and 9 percent of their infants had no insurance coverage 12 - 18 months later.

\section{Measures of health}

In most studies, child and maternal health are ascertained through survey questions to mothers. We construct three different measures of poor child health that draw on information from the medical records and surveys and we assess the robustness of our results to the choice of measure. For the mothers, we rely primarily on information from the medical records, but use baseline self-reported health status in certain analyses. For the fathers, we rely exclusively on survey data.

\section{Child's health}

The first measure of poor child health (severe infant health condition), coded from the medical records and one-year maternal reports of child disability, is whether the infant had a severe abnormal condition at birth and/or was very low birth weight ( $<1500$ grams). Very low birth weight is associated with a number of serious child health problems (Reichman 2005). The coding of the abnormal conditions was conducted by an outside pediatric consultant who was directed to code a case as having poor child health if the child had a condition that is severe, chronic, unlikely caused by maternal prenatal behavior, and in the case of one-year maternal reports, likely present at birth. Our goal was to capture conditions that are for the most part

\footnotetext{
${ }^{5}$ Sample characteristics are presented in Table 2 for the 1,602 mothers who had public insurance at birth and no missing data and for the 806 mothers who had private insurance at birth and no missing data. Multivariate analyses of child insurance loss include 1603 publicly insured cases and 807 privately insured cases for which there were no missing data.
} 
random (e.g., Down Syndrome, congenital heart malformations), given that the pregnancy resulted in a live birth. Four percent of the publicly insured children and 3 percent of the privately insured children in our sample had a severe infant health condition as we have defined it (Table 2).

The second measure of poor child health is low birth weight $(<2500$ grams). Birth weight was obtained from the medical records. Of mothers with public insurance at baseline, 12 percent had low birth weight infants. In contrast, only 6 percent of infants born to mothers with private insurance were low birth weight. This measure is readily obtained from maternal reports or medical records, ${ }^{6}$ but is not very specific because few moderately low birth weight children (the majority of low birth weight children), those weighing between 1500 and 2500 grams, have severe health problems (Reichman 2005). The advantage of this measure is that it conforms to the standard definition of low birth weight and is comparable across studies.

Our third measure is a direct, but broader, measure of infant health—whether the infant had a severe or moderately severe abnormal condition. These include conditions that may or may not have poor long-term prognoses and for which the links to maternal prenatal behavior are weak. $^{7}$ We call this measure any infant health condition. Again, the coding was conducted by an outside pediatric consultant who systematically reviewed the medical record data on infant conditions, as well as data from the one-year interviews on physical disabilities of the child. One fifth of the children in the sample were coded as having any infant health condition ( $20 \%$ of the publicly insured group, $19 \%$ of the privately insured group).

Finally, in supplemental analyses, we use the mother's report of the child's health at the one-year follow-up survey (good, fair, or poor, compared to excellent or very good). Among

\footnotetext{
${ }^{6}$ The correlation of birth weights from the two sources in our data is .98 .

${ }^{7}$ Examples of conditions considered moderately severe are hydrocephaly and cleft palate.
} 
children with public insurance, 15 percent were reported as having less than very good health, compared to 9 percent of children with private insurance.

It is noteworthy that for the two measures of poor child health that were constructed with the goal of capturing random "shocks"-severe abnormal infant condition and any infant health condition - the rates by type of insurance at baseline are virtually identical. In contrast, for both low birth weight and maternal reports of child health status, there are large disparities by baseline health insurance status, which likely reflect—at least in part—differences in socioeconomic status and health behaviors between the two groups.

\section{$\underline{\text { Mother's health }}$}

From information in the mothers' medical records, we constructed measures of physical and mental health status prior to the pregnancy. The mother is coded as having a pre-existing physical health condition if she had one or more of the following health conditions indicated in her medical history--lung disease, cardiac disease, chronic diabetes, hypertension, or liver disease. The mother was coded as having a pre-existing mental illness if there was any documentation of a diagnosed DSM-IV mental disorder (e.g., depression, anxiety, bipolar disorder, schizophrenia, anorexia, suicidality, and mental retardation) in her chart. ${ }^{8}$ In a supplemental analysis, we instead use mothers' self-reported health status (good, fair, or poor, compared to excellent or very good) from the baseline survey.

Mothers with public insurance at baseline were much more likely than mothers with private insurance to have health conditions that pre-dated the birth (Table 2). The difference is most striking for mental illness, with twice as many mothers with public insurance having a

\footnotetext{
${ }^{8}$ Substance abuse disorders were not included in this measure.
} 
history of diagnosed mental illness (12\%) as mothers whose births were covered by private insurance $(6 \%)$.

$\underline{\text { Father's health }}$

We include the father's self-reported health (good, fair, or poor, compared to excellent or very good) from the baseline survey, as well as his score from the Center for Epidemiologic Studies Depression Scale (CES-D), which was included in the fathers' baseline interview. The CES-D scale ranges from 0 (low risk for depression) to 7 (high risk for depression). These are the only analysis variables for which we relied solely on father reports. To avoid sample loss due to missing data, we included a dummy variable indicating that the father did not complete a baseline interview. The prevalence of self-reported suboptimal health status and mean depression scores were higher for fathers having children with mothers on public insurance than for those having children with mothers whose births were covered by private insurance.

\section{Covariates}

We include several covariates that may be related to both health and health insurance status. These include whether the focal child is male and whether the father had insurance from his last employer (41\% for the publicly insured mothers, versus $70 \%$ for the privately insured mothers). We also include whether the parents were married, cohabiting, or not living together at baseline. Among mothers with public insurance at baseline, 89 percent of the parents were unmarried and almost half (47\%) of the unmarried mothers lived with the child's father. Among mothers with private insurance at baseline, half (52\%) were unmarried and 58 percent of the unmarried mothers lived with the child's father.

We include whether the mother and father had any other children together, whether the mother had any children with another partner at the time of the baseline interview, and whether 
the father had at least one child with another partner at the time of the mother's one year followup interview. ${ }^{9}$ Overall, multiple partner fertility is much higher in the public insurance group than in the private insurance group. We also include whether the father visited the mother or baby in the hospital (78\% for the publicly insured group, compared to $92 \%$ for the privately insured group) and whether the mother knew the father at least 12 months prior to conception of the focal child ( $81 \%$ versus $92 \%)$.

We include the mother's age, race/ethnicity, education, and whether she worked within the two-year period preceding the child's birth, as well as her number of previous pregnancies (whether they resulted in live births or not, and including both spontaneous and induced abortions), which was obtained from the mother's medical record. Mothers with public insurance at baseline were younger, less educated, and more likely to be black or Hispanic than mothers with privately insured births.

We include detailed information on the father, whether or not he lived in the household at the time of the birth. We include the father's age (expressed as the number of years the father's age exceeded the mother's age), whether the father was a different race/ethnicity than the mother, whether the father had fewer years of education than the mother, whether the father had ever served in the military, and whether the father was employed at the time of the birth. The fathers in the public insurance group were less likely to have served in the military and to have been employed than those in the private insurance group.

As a proxy for household income, we include the percentage of households in the mother's census tract with income under the poverty line (21\% for the publicly insured group,

\footnotetext{
${ }^{9}$ Data limitations make it impossible to ascertain whether the father had any children with another partner at the time of the baseline.
} 
compared to $13 \%$ for the privately insured group). ${ }^{10}$ Because of the strong associations found in past studies between nativity and health insurance status, we include two measures of parents' immigrant status - (1) whether the mother, but not the father, is an immigrant; and (2) whether both parents are immigrants (both compared to the father only or neither parent is an immigrant). There are no differences across groups in nativity status. Finally, for reasons stated earlier, all models include state fixed effects.

\section{Other measures}

In supplemental analyses, we included whether the mother had a previous low birth weight, small for gestational age, or preterm birth (from the medical records) or whether the mother received first prenatal trimester care (from the medical records). Mothers with publicly insured births were much more likely to have had a previous adverse birth outcome $(10 \%$, compared to $6 \%)$ and much less likely to have received first trimester prenatal care $(51 \%$, compared to $70 \%)$.

\section{Modeling Strategy}

We are interested in estimating the effects of the child's, mother's, and father's health status on insurance loss of both the mother and child. We use probit models to estimate the following equation, separately for mothers and children:

Insurance Loss $=f$ (child's health, mother's health, father's health, other child characteristics, parent relationship status, other mother and father characteristics, state fixed effects, $\mu$ )

The estimation of this model is straightforward, assuming that health is truly random (exogenous). It is possible, however, that there are non-random components of health (reflected

\footnotetext{
${ }^{10}$ In this sample, there is an average of 1.65 births per census tract, with 65 percent of the 1453 tracts containing only one birth.
} 
in $\mu$ ) that are correlated with unobserved determinants of insurance loss. If that is the case, health would be endogenous and the estimated effects of child, mother, and father health on insurance loss would be biased. In theory, one could use instrumental variables estimation to obtain unbiased estimates. However, in this case, the probability of finding valid identifiers for health status (i.e., measures that are strongly related to health status but affect health insurance only through health) is extremely low. We address the potential endogeneity issue by: (1) using longitudinal data, which helps in establishing the temporal ordering of events (our measures of health status and most covariates precede the change in insurance status); (2) attempting to measure child health conditions that are exogenous; and (3) using rich data and including numerous covariates that are associated with both health and health insurance, as well as state fixed effects. We assess the robustness of our results to a number of different model specifications and explore competing explanations.

\section{Multivariate Results}

The results from probit models of insurance loss are presented in Table 3 (for children) and Table 4 (for mothers). In each cell of results, the probit coefficient appears on top, the marginal effect is in brackets, and the standard error, which is corrected for state clustering of observations using the Huber-White method, is in parentheses.

\section{Children's Insurance Loss}

Regardless which measure of poor child health is used, there is no significant association between child health and loss of insurance among children whose mothers had public insurance at the time of the birth. ${ }^{11}$ In contrast, previous studies have found that for children enrolled in

\footnotetext{
${ }^{11}$ Sample sizes precluded using severe infant health condition as the measure of poor child health when estimating insurance loss among children whose births were covered by private insurance.
} 
public insurance, poor child health decreases the likelihood of insurance gaps (Sommers 2005, Haley and Kenney 2003, Schenkman et al. 2002). The inconsistency may reflect the ages of children studied, the measures of health used, or the policy context. All three previous studies used samples of children ages 0 to 18 . Sommers and Haley \& Kenney used maternal reports of children's health. Schenkman et al. used documented child health conditions of children in one state-Florida. For privately insured births, the only measure of child health that is significantly associated with insurance loss is our broadest—any infant health condition.

There are strong associations between parental health and children's insurance loss. For publicly insured births, a maternal physical health condition reduces the likelihood of insurance loss for the child by 6 percentage points, while a pre-existing diagnosed maternal mental illness increases the probability that the child will become uninsured by 9 percentage points. The latter finding is consistent with past research indicating that women who report a mental health problem are more likely than those who report having no mental health problems to perceive barriers to enrolling in Medicaid (Stuber and Bradley 2005). For publicly insured births, children of fathers with higher depression scores have lower rates of insurance loss, all else equal. Finally, for privately insured births, the only significant effect of parental health is for father-reported suboptimal health at baseline_-poor self-reported health increases the likelihood that the child becomes uninsured by 5 to 6 percentage points. There is no association between the father's selfreported health status and the child's loss of insurance for births that were publicly insured.

The covariate estimates are very robust to the measure of poor child health that is used. The effects, generally, are more pronounced for those with private insurance at baseline than for those who had public insurance. The father having had health insurance through his last employer reduces the probability that a privately insured child will lose insurance, as do the 
parents having other children together and the mother having attended college. For publicly insured births, the father having served in the military decreases the risk that the child will lose insurance coverage. If the father has a low level of education relative to the mother, the risk of the child's insurance loss increases by 4-5 percentage points. Regardless of the type of insurance at birth, both parents being immigrants is a strong and consistent positive predictor of the child being uninsured at age 1 .

\section{Mothers' Insurance Loss}

Many of the patterns for mother's insurance loss are similar to those for child's insurance loss. However, there are some notable differences and, overall, there are more significant associations.

As was the case for children's public insurance loss, we find that the health of the child is not significantly associated with a loss of health insurance for the mother. However, among those who had public insurance for the birth, the mother's own health has strong effects. Publicly insured mothers with a physical health problem are 7 percentage points less likely to lose insurance coverage than those without physical health problems, all else equal, and mothers with a history of mental illness are 8-9 percentage points more likely than those without a history of mental illness to lose insurance coverage. For privately insured births, if the father reported suboptimal health at baseline, the mother was significantly more likely to lose health insurance coverage, and neither the mother's nor the child's health status is associated with the mother's health insurance status at age 1 . These results are very similar to what we found for children's health insurance loss. However, the father's depression score, which significantly decreased the likelihood of insurance loss among children whose births were covered by public insurance, and 
any infant health condition, which significantly decreased the risk of insurance loss among privately insured children, are not associated with insurance loss among mothers.

The father having had insurance through his last employer reduces the likelihood that privately insured mothers lose coverage, as does the parents having been married at baseline (versus cohabiting). Multiple partner fertility (the mother having had children with other fathers or the father having had children with other mothers) is negatively associated with insurance loss among mothers who were publicly insured for the birth. Publicly insured mothers who are high school graduates are less likely to lose insurance than those with less than a high school education, and regardless of insurance status at the time of the birth, being a college graduate reduces the risk of becoming uninsured. Among publicly insured mothers, the father being older than the mother and the father being less educated than the mother are risk factors for insurance loss, and the poorer her census tract, the less likely that the mother loses insurance. Finally, consistent with prior findings, publicly insured mothers who are immigrants (Angel, Frias, and Hill 2005) and who are Hispanic (Holahan, Dubay, and Kenney 2003, Schoen and DesRoches 2000) are at increased risk of becoming uninsured. The risk is particularly high when the father is also an immigrant—both parents being immigrants increases the likelihood that the mother loses public insurance by 23 percentage points.

\section{Auxiliary Analyses}

We estimated a number of supplemental models to assess the robustness of our results to alternative sources of reports and explore competing explanations. ${ }^{12}$

\section{$\underline{\text { Measures based on alternative sources of reports }}$}

We estimated models that include the mother's report of the child's health (good, fair, or poor compared to excellent or very good) from the one-year follow-up survey instead of the

\footnotetext{
${ }^{12}$ The results from supplementary analyses are not shown, but are available upon request.
} 
other child health measures, and her self-report of her own general health status at baseline (good, fair, or poor compared to excellent or very good). We found that maternal reports of child health are not associated with insurance loss of mothers but that they are associated with a decreased likelihood of insurance loss among children who were initially on public insurance (8 percentage points). The result for children is consistent with findings from previous studies that used maternal reports of children's health status (Sommers 2005, Haley and Kenney 2003), suggesting that perceptions of poor child health, rather than actual child health conditions, lead to publicly insured children's continued coverage. Self-reported maternal health is not significantly associated with insurance loss of children or mothers regardless of baseline insurance status.

\section{Competing explanations}

A limitation of our data is that we have little information on the health of the mother's other children, which could confound the effects of the focal child's, mother's, or father's health on the mother's or children's health insurance status. We address this limitation by estimating models that control for whether the mother had a previous adverse birth outcome (low birth weight, small for gestational age or preterm delivery). The estimated effects of child's, mother's and father's health status on the mother's and child's health insurance were insensitive to the inclusion of this measure. In addition, we found that for publicly insured births, the mother having had a previous adverse birth outcome reduced the likelihood that the mother or child became uninsured (mothers were 6-7 percentage points less likely and children were 4-5 percentage points less likely to lose coverage). There were no significant effects for those covered by private insurance.

It is possible that insurance status prior to the pregnancy or during the prenatal period affects both health (mother or child) and subsequent insurance status. To address this possibility, 
we estimated a set of models that included whether the mother received first trimester prenatal care. We found that including first trimester care in the models did not change any of the estimated effects of health on the mother's or child's loss of insurance. Additionally, first trimester care was negatively associated with insurance loss— by about 6 percentage points among privately insured children and mothers and by about 4 percentage points among publicly insured children. There was no association for publicly insured mothers.

\section{Conclusion}

We found that in the Fragile Families and Child Wellbeing birth cohort study of urban, mostly unmarried parents and their children, virtually all births were covered by health insurance, but that a substantial number of the mothers and children did not have any health insurance one year later. We examined why this was the case, even after the SCHIP legislation of 1997 dramatically reduced the number and rates of uninsured children in the U.S. We focused on the potential roles of the child's, the mother's, and the father's health status. We found that there are complicated interdependencies between health and insurance status within the mother-fatherchild triad.

We found that child health is, for the most part, not associated with insurance loss of mothers or their children. Although previous research cited earlier has shown that poor child health decreases the labor supply of both mothers and fathers and that it increases the likelihood that the parents do not live together, we found that these effects do not translate into an increased probability that mothers, even among those with private insurance, lose health insurance or that publicly insured children become uninsured. That is, the family turbulence caused by the shock of poor child health does not result in the family becoming uninsured. 
In contrast, there are strong associations between parents' health and children's insurance loss. Among publicly insured children, those whose mothers have physical health conditions are less likely to become uninsured than those whose mothers are healthy. Their mothers are also less likely to lose health insurance. However, maternal mental illness increases the likelihood that both the mother and the child become uninsured by age 1 . These results indicate that while mothers in poor physical health are able to maintain the coverage they need and to keep their children insured, there is a gap in the public safety net for mothers with mental illness and their children.

The results for maternal mental illness have dire implications. Mothers with mental illness who lack coverage are less likely than those with health insurance to get appropriate mental health services (MacAlpine and Mechanic 2000). Mental health disorders are a leading cause of disability worldwide, accounting for one-third of total years lived with disability (World Health Organization 2003). To reduce the disability burden and enable mothers to lead productive lives, access to mental health services is essential. Furthermore, mental health of mothers can affect their children's health and development. Past research has found that mothers with depression have a difficult time managing their young children's medical care (Minkovitz et al. 2005) and that mothers experiencing post-partum depression are less likely to breastfeed, play with their children, read to them, and follow daily routines than mothers without post-partum depression (McLearn et al. 2006). Similar issues with managing child health care and parenting practices may arise with mothers with other mental illnesses. These unfavorable parenting practices may lead to cognitive, social and emotional problems among children (Coiro 1997). Since information on mothers' mental health status is often available in mothers' medical records, the hospital of delivery would be a convenient checkpoint for educating mothers with 
diagnosed mental illnesses about the availability and importance of postnatal health insurance coverage for both themselves and their children, and for establishing a follow-up plan to insure that they and their children do not get lost in the system.

Fathers' health also affects their children's health insurance coverage. Privately insured children whose fathers are in poor physical health are more likely than those whose fathers are in good health to become uninsured by age 1, as are the mothers. This result suggests the need for subsidies that enable men in poor health to afford health insurance for themselves and their dependents.

The covariate estimates underscore that health insurance status is very much a family affair. For example, insurance loss among publicly insured mothers is strongly related to both parents' low levels of human capital and both parents being immigrants (but not only the mother being an immigrant) is a risk factor for the child being uninsured at age 1, regardless of health insurance type at the time of the birth.

We conclude with two caveats. Despite our rich longitudinal data and strategies for minimizing endogeneity, it is possible that the associations we uncovered do not represent causal effects. It is also possible that we have not correctly characterized the temporal ordering of events. Regardless of these limitations, however, this study has produced include important policy-relevant facts about the determinants of health insurance status in the post-PRWORA post-SCHIP era and the strong interdependencies of family members' health and insurance status. 


\section{References}

Aiken, Kimberly D., Freed, Gary L., and Matthew M. Davis. 2004. "When Insurance Status Is Not Static: Insurance Transitions of Low-Income Children and Implications for Health and Health Care." Ambulatory Pediatrics 4(3): 237-243.

Aizer, Anna and Jeffrey Grogger. 2003. "Parental Medicaid Expansions and Health Insurance Coverage.” NBER Working Paper 9907, http://www.nber.org/papers/w9907.

Angel, Ronald J., Frias, Sonia M., Terrence D. Hill. 2005. "Determinants of Household Insurance Coverage Among Low-Income Families from Boston, Chicago and San Antonio: Evidence from the Three-City Study." Social Science Quarterly 86(5): 13381353.

Ayanian, John Z., Weissman, Joel S., Schneider, Eric C., Ginsburg, Jack A., and Alan M. Zaslavsky. 2000. "Unmet Health Needs of Uninsured Adults in the United States." Journal of the American Medical Association 284(16): 2061-2069.

Baker, David W., Sudano, Joseph J., Albert, Jeffrey M., Borawski, Elaine A., and Avi Dor. 2002. "Loss of Health Insurance and the Risk for a Decline in Self-Reported Health and Physical Functioning.” Medical Care 40(11): 1126-1131.

Blumberg, Linda J. and Len M. Nichols. 2001. "The Health Status of Workers Who Decline Employer-Sponsored Coverage." Health Affairs 20(6): 180-187.

Bundorf, M. Kate, Bradley Herring and Mark Pauly. 2005. "Health Risk, Income, and the Purchase of Private Health Insurance.” NBER Working Paper 11677, http://www.nber.org/papers/w11677.

Busch, Susan H. and Noelia Duchovny. 2005. "Family coverage expansions, Impact on Insurance Coverage and Health Care Utilization of Parents." Journal of Health Economics 24(5): 876-890.

Coiro, Mary Jo. 1997. "Maternal Depressive Symptoms as a Risk Factor for the Development of Children in Poverty", in Moore, K.A. Factors in the Development of Children in Welfare Families: An Ecological Perspective. Symposium presented at the meetings of the Society for Research in Child Development, Washington DC.

Corman, Hope, Noonan, Kelly, and Nancy E. Reichman. 2005. Mothers' Labor Supply in Fragile Families: The Role of Child Health. Eastern Economic Journal 31(4): Forthcoming.

Currie, Janet and Jonathan Gruber. 1996. "Health Insurance Eligibility, Utilization of Medical Care, and Child Health." Quarterly Journal of Economics 111(2): 431-466. 
Desai, Mayur M., Bruce, Martha Livingston, Desai, Rani A., and Benjamin G. Druss. 2001. "Validity of Self-reported Cancer History: A Comparison of Health Interview Data and Cancer Registry Records." American Journal of Epidemiology 153(3): 299-306.

Dubay, Lisa and Genevieve Kenney. 2003. "Expanding Public Health Insurance to Parents: Effects on Children's Coverage under Medicaid." Health Services Research 38(5): 12831301.

Goldman, Noreen, Lin, I-Fen, Weinstein, Maxine, and Yu-Hsuan Lin. 2003. "Evaluating the Quality of Self-Reports of Hypertension and Diabetes." Journal of Clinical Epidemiology 56(2): 148-154.

Hadley, Jack. 2002. "Sicker and Poorer: The Consequences of Being Uninsured." Medical Care Research Review 60(2): 3S-75S.

Haley, Jennifer and Genevieve Kenney. 2003. "Coverage Gaps for Medicaid-Eligible Children in the Wake of Federal Reform." Inquiry 40(2): 158-168.

Hanson, Karla L. 1998. "Is Insurance Enough? The Link Between Parents' and Children's Health Care Use Revisited." Inquiry 35(3): 294-302.

Holahan, John, Dubay, Lisa, and Genevieve Kenney. 2003. "Which Children Are Still Uninsured and Why?" The Future of Children 13(1): 55-79.

Kasper, Judith D., Giovanni, Terence A., and Catherine Hoffman. 2002. "Gaining and Losing Health Insurance: Strengthening the Evidence on Access to Care and Health Outcomes." Medical Care Research and Review 57(3): 298-318.

Levy, Helen and David Meltzer. 2001. "What Do We Really Know About Whether Health Insurance Affects Health? Economic Research Initiative on the Uninsured." ERIU Working Paper 6, www.umich/ eriu.wp6.pdf.

MacAlpine, Donna D. and David Mechanic. 2000. "Utilization of Specialty Mental Health Care Among Persons with Severe Mental Illness: The Roles of Demographics, Need, Insurance and Risk." Health Services Research 35(1), Part II: 277-292.

McLearn, Kathryn Taaffe, Minkovitz, Cynthia S, Strobino, Donna M., Marks, Elisabeth and William Hou. 2006. "Maternal Depressive Symptoms at 2 to 4 Months Post Partum and Early Parenting Practices." Archives of Pediatric and Adolescent Medicine 160: 279-284

Miller, Jane E., Gaboda, Dorothy, Cantor, Joel C. and Thomas Trail. 2005. "New Evidence on SCHIP Retention and Subsequent Insurance Status: The Roles of Child Health and Parental Eligibility." Presented at the Academy Health Conference, Boston. 
Minkovitz, Cynthia S., Strobino, Donna, Scharfstein, Dan, Hou, William,Miller, Tess, Mistry, Kamila and Karen Swartz. 2005. "Maternal Depressive Symptoms and Children's Receipt of Health Care in the First 3 Years of Life." Pediatrics 115(2):306-314.

Newacheck, Paul W., Stoddard, Jeffrey J., Hughes, Dana C., and Michelle Pearl. 1998. "Health Insurance and Access to Primary Care for Children." New England Journal of Medicine 338(8): 513-19.

Noonan, Kelly, Reichman, Nancy E., and Hope Corman. 2005. "New Fathers' Labor Supply: Does Child Health Matter?" Social Science Quarterly 86(5): 1399-1417(19).

Olson, Lynn M, Tang, Suk-fong S., and Paul Newacheck. 2005. "Children in the United States with Discontinuous Health Insurance Coverage." The New England Journal of Medicine 353(4): 382-391.

Reichman, Nancy E. 2005. "Low Birth Weight and School Readiness." The Future of Children 15(1): 91-116.

Reichman, Nancy E., Corman, Hope, and Kelly Noonan. 2004. "Effects of Child Health on Parents' Relationship Status.” Demography 41(3): 569-584.

Reichman, Nancy E., Corman, Hope, and Kelly Noonan. 2006. "Effects of Child Health on Sources of Public Support." Southern Economic Journal Forthcoming.

Satchell, Marlon and Susmita Pati. 2005. "Insurance Gaps Among Vulnerable Children in the United States, 1999-2001.” Pediatrics 116(5): 1155-1161.

Schoen, Cathy and Catherine DesRoches. 2000. "Uninsured and Unstably Insured: the Importance of Continuous Insurance Coverage." Health Services Research 35 (1 Pt 2): $187-206$.

Shenkman, Elizabeth, Vogel, Bruce, Boyett, James, and Rose Naff. 2002. "Disenrollment and Re-enrollment Patterns in a SCHIP." Health Care Financing Review 23(3): 47-63.

Sommers, Benjamin D. 2005. "The Impact of Program Structure on Children's Disenrollment from Medicaid and SCHIP.” Health Affairs 24(6): 1611-1618.

Spillman, Brenda C. 2000. "Adults Without Health Insurance: Do State Policies Matter?" Health Affairs 19(4): 178-187.

Stuber, Jennifer and Elizabeth Bradley. 2005. "Barriers to Medicaid Enrollment: Who is at Risk?" American Journal of Public Health 95(2): 292-298.

Swartz, Katherine, Marcotte, John and Timothy D. McBride. 1993. "Personal Characteristics and Spells Without Health Insurance.” Inquiry 30: 64-76. 
World Health Organization (WHO). 2003. Investing in Mental Health. www.who.int/mental_health/media/investing_mnh.pdf.

Zhu, Khangmin, McKnight, Barbara, Stergachis, Andy, Daling, Janet R., and Robert S. Levine. 1999. "Comparison of self-report data and medical records data: results from a casecontrol study on prostate cancer." International Journal of Epidemiology 28(3): 409-417. 
Table 1: Loss of Health Insurance Between Baseline and One Year Follow-up

\begin{tabular}{rrrcc}
\hline \multirow{2}{*}{ Mother } & & \multicolumn{3}{c}{ Child } \\
\cline { 3 - 5 } & No & No & Yes & Total \\
\cline { 3 - 5 } & Yes & 1,658 & 37 & 1,695 \\
& Total & 445 & 260 & 705 \\
& & 2,103 & 297 & 2,400 \\
\hline
\end{tabular}


Table 2: Sample Characteristics (proportions, unless indicated otherwise)

\section{Lost Health Insurance}

Mother

.14

Child

\section{Child Characteristics}

Severe Infant Health Condition $\quad .04$

.03

Low Birth Weight

Any Infant Health Condition

Male Child

Suboptimal Health (mother report at 1 year)

\section{Mother's Health}

Maternal Physical Health Problem

Disposed Mental Illness

Self-Reported Suboptimal Health

\section{Father's Health \& Health Insurance}

Self-Reported Suboptimal Health

Depression score (CES-D), mean

Married at Baseline*

Not Cohabiting

Knew Father at Least 12 Months

Parents Have Other Children Together

\section{Mother's Other Characteristics}

Age, mean

Age Squared

Less Than High School* 


\section{Public Insurance at Baseline Private Insurance at Baseline}

Mother's Other Characteristics (cont'd)

Hispanic

Other Race/Ethnicity

Number of Previous Pregnancies, mean

Previous Adverse Birth Outcome

First Trimester Prenatal Care
Mother), mean

Different Race/Ethnicity Than Mother

Less Educated Than Mother

Served in the Military

Employed at Baseline

Did Not Complete Baseline Interview

\section{Other Characteristics}

\% Below Poverty in Mother's Census Tract, mean

.05

Mother (but not father) is an Immigrant

.10

.85

Only Father or Neither Parent is an Immigrant*

$\mathrm{N}$

1602
.16

.33

.12

.86

.11

.10

.24

.73

.06

70

.85

806

Notes: Standard Deviations in parentheses.

*Reference category in regression analyses. 


\begin{tabular}{cc}
$\begin{array}{c}\text { Child Had Public Insurance at } \\
\text { Baseline }\end{array}$ & $\begin{array}{c}\text { Child Had Private Insurance at } \\
\text { Baseline }\end{array}$ \\
\hline Coefficient & Coefficient \\
(Standard Error) & (Standard Error) \\
[Marginal Effect] & [Marginal Effect] \\
\hline
\end{tabular}

Severe Infant Health

$-.00$

$(.23)$

[-.00]
Low Birth Weight

Male Child

Maternal Physical Health

Problem

Maternal History of Mental Illness

Father's Self-Reported

Suboptimal Health

Father's Depression score (CES-D)

Father had Health Insurance

from Last Employer

Cohabiting at Baseline

Any Infant Health Condition

$$
\begin{gathered}
.19 \\
(.14) \\
{[.04]}
\end{gathered}
$$

$-.48$

(.34)

[-.04]
.02

$(.09)$

[.00]

$\begin{array}{ccc}-.16^{* *} & -.16^{* *} & -.16^{* *} \\ (.08) & (.08) & (.08) \\ {[-.03]} & {[-.03]} & {[-.03]}\end{array}$

$-.30 *$

(.17)

[-.06]

$-.30 *$

(.17)

[-.06]

$.37 * * *$

(.08)

[.09]

$.36^{* * * *}$

(.09)

[.09]

$-.13$

(.10)

[-.03]

$$
-.13
$$

(.10)

[-.03]

$-.30^{*}$
$(.17)$
$[-.06]$

[-.06]

$.37 * * *$

(.09)

[.09]

$-.13$

(.10)

[-.03]

$-.05 * *$

(.02)

[-.01]

$-.05 * *$

(.02)

[-.01]

$-.05 * *$

(.02)

[-.01]

$-.09$

(.09)

[-.02]

$-.09$

(.09)

[-.02]

$-.09$

(.09)

[-.02]

$-.01$

(.11)

[-.00]

(.11)

[-.00]
$-.01$

(.11)

[-.00]
.11

(.16)

[.01]

$-.08$

(.20)

[-.01]

$-.01$

(.17)

[-.00]

$.42 * * *$

(.15)

[.06]

$-.02$

(.04)

[-.00]

$-.48 * *$

(.21)

[-.06]

.25

(.19)

[.03]
$-.49 * * *$

(.17)

[-.04]

.14

(.16)

[.01]

[.01]

$-.09$

(.20)

[-.01]

$(.22)$

[-.01]

$\begin{array}{ll}.02 & -.01\end{array}$

(.19) (.20)

[.00] [-.00]

$.40 * * * \quad .40 * * *$

(.14) (.15)

[.05] [.05]

$\begin{array}{ll}-.01 & -.01\end{array}$

(.04) (.05)

$[-.00] \quad[-.00]$

$\begin{array}{cc}-.44 * * & -.45 * * \\ (.21) & (.21) \\ {[-.06]} & {[-.06]}\end{array}$

.24

.26

(.19)

(.18)

[.03] 


\begin{tabular}{|c|c|c|c|c|c|c|}
\hline \multirow[b]{2}{*}{ Not Cohabiting } & \multicolumn{3}{|c|}{$\begin{array}{c}\text { Child Had Public Insurance at } \\
\text { Baseline } \\
\text { Coefficient } \\
\text { (Standard Error) } \\
\text { [Marginal Effect] } \\
\end{array}$} & \multicolumn{3}{|c|}{$\begin{array}{c}\text { Child Had Private Insurance at } \\
\text { Baseline } \\
\text { Coefficient } \\
\text { (Standard Error) } \\
\text { [Marginal Effect] }\end{array}$} \\
\hline & $\begin{array}{c}-.06 \\
(.11) \\
{[-.01]}\end{array}$ & $\begin{array}{c}-.06 \\
(.12) \\
{[-.01]}\end{array}$ & $\begin{array}{c}-.06 \\
(.12) \\
{[-.01]}\end{array}$ & $\begin{array}{c}.02 \\
(.31) \\
{[.00]}\end{array}$ & $\begin{array}{c}.00 \\
(.32) \\
{[.00]}\end{array}$ & $\begin{array}{c}.05 \\
(.32) \\
{[.01]}\end{array}$ \\
\hline $\begin{array}{l}\text { Mother Knew Father at Least } \\
12 \text { Months }\end{array}$ & $\begin{array}{l}-.05 \\
(.08) \\
{[-.01]}\end{array}$ & $\begin{array}{c}-.04 \\
(.08) \\
{[-.01]}\end{array}$ & $\begin{array}{c}-.05 \\
(.08) \\
{[-.01]}\end{array}$ & $\begin{array}{c}-.27 \\
(.18) \\
{[-.04]}\end{array}$ & $\begin{array}{c}-.28 \\
(.18) \\
{[-.04]}\end{array}$ & $\begin{array}{c}-.25 \\
(.18) \\
{[-.03]}\end{array}$ \\
\hline $\begin{array}{l}\text { Parents Have Other Children } \\
\text { Together }\end{array}$ & $\begin{array}{c}-.07 \\
(.10) \\
{[-.01]}\end{array}$ & $\begin{array}{c}-.07 \\
(.10) \\
{[-.01]}\end{array}$ & $\begin{array}{c}-.07 \\
(.10) \\
{[-.01]}\end{array}$ & $\begin{array}{c}-.25 * \\
(.14) \\
{[-.03]}\end{array}$ & $\begin{array}{c}-.23^{*} \\
(.13) \\
{[-.02]}\end{array}$ & $\begin{array}{c}-.24 * \\
(.14) \\
{[-.02]}\end{array}$ \\
\hline $\begin{array}{l}\text { Mother has Children with } \\
\text { Other Partner }\end{array}$ & $\begin{array}{c}.03 \\
(.14) \\
{[.01]}\end{array}$ & $\begin{array}{c}.03 \\
(.14) \\
{[.01]}\end{array}$ & $\begin{array}{c}.03 \\
(.14) \\
{[.01]}\end{array}$ & $\begin{array}{c}-.24 \\
(.20) \\
{[-.02]}\end{array}$ & $\begin{array}{c}-.21 \\
(.20) \\
{[-.02]}\end{array}$ & $\begin{array}{c}-.23 \\
(.18) \\
{[-.02]}\end{array}$ \\
\hline $\begin{array}{l}\text { Father has Children with } \\
\text { Other Partner }\end{array}$ & $\begin{array}{c}-.13 \\
(.08) \\
{[-.03]}\end{array}$ & $\begin{array}{c}-.13 \\
(.08) \\
{[-.03]}\end{array}$ & $\begin{array}{c}-.13 \\
(.08) \\
{[-.03]}\end{array}$ & $\begin{array}{c}.08 \\
(.18) \\
{[.01]}\end{array}$ & $\begin{array}{l}.10 \\
(.18) \\
{[.01]}\end{array}$ & $\begin{array}{c}.07 \\
(.19) \\
{[.01]}\end{array}$ \\
\hline Father Visited in Hospital & $\begin{array}{c}.01 \\
(.15) \\
{[.00]}\end{array}$ & $\begin{array}{c}.01 \\
(.15) \\
{[.00]}\end{array}$ & $\begin{array}{c}.02 \\
(.15) \\
{[.00]}\end{array}$ & $\begin{array}{c}.01 \\
(.32) \\
{[-.00]}\end{array}$ & $\begin{array}{c}.04 \\
(.31) \\
{[.00]}\end{array}$ & $\begin{array}{c}.06 \\
(.31) \\
{[.01]}\end{array}$ \\
\hline Mother's Age & $\begin{array}{c}-.04 \\
(.06) \\
{[-.01]}\end{array}$ & $\begin{array}{c}-.04 \\
(.06) \\
{[-.01]}\end{array}$ & $\begin{array}{c}-.04 \\
(.06) \\
{[-.01]}\end{array}$ & $\begin{array}{c}.01 \\
(.18) \\
{[.00]}\end{array}$ & $\begin{array}{c}.00 \\
(.13) \\
{[.00]}\end{array}$ & $\begin{array}{c}.00 \\
(.13) \\
{[.00]}\end{array}$ \\
\hline Mother's Age Squared & $\begin{array}{c}.00 \\
(.00) \\
{[.00]}\end{array}$ & $\begin{array}{c}.00 \\
(.00) \\
{[.00]}\end{array}$ & $\begin{array}{c}.00 \\
(.00) \\
{[.00]}\end{array}$ & $\begin{array}{c}.00 \\
(.00) \\
{[.00]}\end{array}$ & $\begin{array}{c}.00 \\
(.00) \\
{[.00]}\end{array}$ & $\begin{array}{c}.00 \\
(.00) \\
{[.00]}\end{array}$ \\
\hline $\begin{array}{l}\text { Mother is High School } \\
\text { Graduate }\end{array}$ & $\begin{array}{c}-.09 \\
(.10) \\
{[-.02]}\end{array}$ & $\begin{array}{c}-.08 \\
(.10) \\
{[-.02]}\end{array}$ & $\begin{array}{c}-.09 \\
(.10) \\
{[-.02]}\end{array}$ & $\begin{array}{c}-.11 \\
(.29) \\
{[-.01]}\end{array}$ & $\begin{array}{c}-.10 \\
(.29) \\
{[-.01]}\end{array}$ & $\begin{array}{c}-.15 \\
(.28) \\
{[-.02]}\end{array}$ \\
\hline $\begin{array}{l}\text { Mother has Some College But } \\
\text { Not Graduate }\end{array}$ & $\begin{array}{c}-.02 \\
(.15) \\
{[-.00]}\end{array}$ & $\begin{array}{c}-.02 \\
(.16) \\
{[-.00]}\end{array}$ & $\begin{array}{c}-.03 \\
(.15) \\
{[-.01]}\end{array}$ & $\begin{array}{c}-.52 * \\
(.28) \\
{[-.05]}\end{array}$ & $\begin{array}{c}-.52 * \\
(.28) \\
{[-.05]}\end{array}$ & $\begin{array}{c}-.54 * \\
(.27) \\
{[-.05]}\end{array}$ \\
\hline
\end{tabular}




\begin{tabular}{|c|c|c|c|c|c|c|}
\hline \multirow[b]{2}{*}{ Mother is College Graduate } & \multicolumn{3}{|c|}{$\begin{array}{c}\text { Child Had Public Insurance at } \\
\text { Baseline } \\
\text { Coefficient } \\
\text { (Standard Error) } \\
\text { [Marginal Effect] } \\
\end{array}$} & \multicolumn{3}{|c|}{$\begin{array}{c}\text { Child Had Private Insurance a } \\
\text { Baseline } \\
\text { Coefficient } \\
\text { (Standard Error) } \\
\text { [Marginal Effect] } \\
\end{array}$} \\
\hline & $\begin{array}{c}.12 \\
(.26) \\
{[.03]}\end{array}$ & $\begin{array}{c}.13 \\
(.26) \\
{[.03]}\end{array}$ & $\begin{array}{c}.12 \\
(.26) \\
{[.03]}\end{array}$ & $\begin{array}{c}-.69 * * \\
(.35) \\
{[-.06]}\end{array}$ & $\begin{array}{c}-.70 * * \\
(.35) \\
{[-.06]}\end{array}$ & $\begin{array}{c}-.73 * * \\
(.35) \\
{[-.06]}\end{array}$ \\
\hline $\begin{array}{l}\text { Mother Worked in Past } 2 \\
\text { Years }\end{array}$ & $\begin{array}{c}-.02 \\
(.12) \\
{[-.00]}\end{array}$ & $\begin{array}{c}-.02 \\
(.12) \\
{[-.00]}\end{array}$ & $\begin{array}{c}-.02 \\
(.12) \\
{[-.00]}\end{array}$ & $\begin{array}{c}-.08 \\
(.19) \\
{[-.01]}\end{array}$ & $\begin{array}{c}-.05 \\
(.20) \\
{[-.01]}\end{array}$ & $\begin{array}{c}-.04 \\
(.20) \\
{[-.00]}\end{array}$ \\
\hline Mother Non-Hispanic Black & $\begin{array}{c}.02 \\
(.10) \\
{[.00]}\end{array}$ & $\begin{array}{c}.02 \\
(.10) \\
{[.00]}\end{array}$ & $\begin{array}{c}.02 \\
(.10) \\
{[.00]}\end{array}$ & $\begin{array}{c}-.14 \\
(.23) \\
{[-.02]}\end{array}$ & $\begin{array}{c}-.15 \\
(.22) \\
{[-.02]}\end{array}$ & $\begin{array}{c}-.15 \\
(.22) \\
{[-.02]}\end{array}$ \\
\hline Mother Hispanic & $\begin{array}{l}.07 \\
(.11) \\
{[.02]}\end{array}$ & $\begin{array}{c}.08 \\
(.10) \\
{[.02]}\end{array}$ & $\begin{array}{c}.07 \\
(.10) \\
{[.02]}\end{array}$ & $\begin{array}{c}-.16 \\
(.21) \\
{[-.02]}\end{array}$ & $\begin{array}{c}-.14 \\
(.21) \\
{[-.02]}\end{array}$ & $\begin{array}{c}-.14 \\
(.21) \\
{[-.01]}\end{array}$ \\
\hline Mother Other Race/Ethnicity & $\begin{array}{c}-.20 \\
(.37) \\
{[-.04]}\end{array}$ & $\begin{array}{c}-.19 \\
(.38) \\
{[-.03]}\end{array}$ & $\begin{array}{c}-.19 \\
(.37) \\
{[-.04]}\end{array}$ & $\begin{array}{c}.09 \\
(.25) \\
{[.01]}\end{array}$ & $\begin{array}{c}.10 \\
(.22) \\
{[.01]}\end{array}$ & $\begin{array}{c}.15 \\
(.24) \\
{[.02]}\end{array}$ \\
\hline $\begin{array}{l}\text { Number of Previous } \\
\text { Pregnancies }\end{array}$ & $\begin{array}{c}-.08 \\
(.12) \\
{[-.02]}\end{array}$ & $\begin{array}{c}-.08 \\
(.12) \\
{[-.02]}\end{array}$ & $\begin{array}{c}-.08 \\
(.12) \\
{[-.02]}\end{array}$ & $\begin{array}{c}-.22 \\
(.20) \\
{[-.03]}\end{array}$ & $\begin{array}{c}-.23 \\
(.19) \\
{[-.03]}\end{array}$ & $\begin{array}{c}-.21 \\
(.20) \\
{[-.02]}\end{array}$ \\
\hline $\begin{array}{l}\text { Age Difference in Years } \\
\text { (Father Minus Mother) }\end{array}$ & $\begin{array}{c}.00 \\
(.01) \\
{[.00]}\end{array}$ & $\begin{array}{c}.00 \\
(.01) \\
{[.00]}\end{array}$ & $\begin{array}{c}.00 \\
(.01) \\
{[.00]}\end{array}$ & $\begin{array}{c}-.02 \\
(.01) \\
{[-.00]}\end{array}$ & $\begin{array}{c}-.02 \\
(.02) \\
{[-.00]}\end{array}$ & $\begin{array}{c}-.02 \\
(.02) \\
{[-.00]}\end{array}$ \\
\hline $\begin{array}{l}\text { Father Different } \\
\text { Race/Ethnicity Than Mother }\end{array}$ & $\begin{array}{l}.12 \\
(.10) \\
{[.02]}\end{array}$ & $\begin{array}{c}.12 \\
(.10) \\
{[.03]}\end{array}$ & $\begin{array}{l}.11 \\
(.10) \\
{[.02]}\end{array}$ & $\begin{array}{c}.22 \\
(.23) \\
{[.03]}\end{array}$ & $\begin{array}{c}.19 \\
(.24) \\
{[.02]}\end{array}$ & $\begin{array}{c}.21 \\
(.24) \\
{[.03]}\end{array}$ \\
\hline $\begin{array}{l}\text { Father Less Educated Than } \\
\text { Mother }\end{array}$ & $\begin{array}{l}.21 * \\
(.12) \\
{[.05]}\end{array}$ & $\begin{array}{c}.20 \\
(.12) \\
{[.04]}\end{array}$ & $\begin{array}{l}.21^{*} \\
(.12) \\
{[.05]}\end{array}$ & $\begin{array}{c}.25 \\
(.20) \\
{[.03]}\end{array}$ & $\begin{array}{c}.26 \\
(.20) \\
{[.03]}\end{array}$ & $\begin{array}{c}.25 \\
(.21) \\
{[.03]}\end{array}$ \\
\hline Father Served in Military & $\begin{array}{c}-.29 * \\
(.17) \\
{[-.05]}\end{array}$ & $\begin{array}{c}-.29 * \\
(.17) \\
{[-.05]}\end{array}$ & $\begin{array}{c}-.29 * \\
(.17) \\
{[-.05]}\end{array}$ & $\begin{array}{c}-.35 \\
(.24) \\
{[-.03]}\end{array}$ & $\begin{array}{c}-.37 \\
(.24) \\
{[-.03]} \\
\end{array}$ & $\begin{array}{c}-.37 \\
(.24) \\
{[-.03]}\end{array}$ \\
\hline
\end{tabular}




\begin{tabular}{|c|c|c|c|c|c|c|}
\hline \multirow[b]{2}{*}{ Father Employed at Baseline } & \multicolumn{3}{|c|}{$\begin{array}{c}\text { Child Had Public Insurance at } \\
\text { Baseline } \\
\text { Coefficient } \\
\text { (Standard Error) } \\
\text { [Marginal Effect }] \\
\end{array}$} & \multicolumn{3}{|c|}{$\begin{array}{c}\text { Child Had Private Insurance at } \\
\text { Baseline } \\
\text { Coefficient } \\
\text { (Standard Error) } \\
\text { [Marginal Effect] } \\
\end{array}$} \\
\hline & $\begin{array}{c}-.02 \\
(.09) \\
{[-.00]}\end{array}$ & $\begin{array}{c}-.03 \\
(.09) \\
{[-.01]}\end{array}$ & $\begin{array}{c}-.02 \\
(.09) \\
{[-.00]}\end{array}$ & $\begin{array}{c}.04 \\
(.24) \\
{[.00]}\end{array}$ & $\begin{array}{c}.01 \\
(.22) \\
{[.00]}\end{array}$ & $\begin{array}{c}.02 \\
(.22) \\
{[.00]}\end{array}$ \\
\hline $\begin{array}{l}\text { Father Did Not Complete } \\
\text { Baseline Interview }\end{array}$ & $\begin{array}{c}-.15 \\
(.11) \\
{[-.03]}\end{array}$ & $\begin{array}{c}-.15 \\
(.11) \\
{[-.03]}\end{array}$ & $\begin{array}{c}-.15 \\
(.11) \\
{[-.03]}\end{array}$ & $\begin{array}{c}-.13 \\
(.27) \\
{[-.01]}\end{array}$ & $\begin{array}{c}-.10 \\
(.29) \\
{[-.01]}\end{array}$ & $\begin{array}{c}-.15 \\
(.28) \\
{[-.01]}\end{array}$ \\
\hline $\begin{array}{l}\% \text { Below Poverty in Mother's } \\
\text { Census Tract }\end{array}$ & $\begin{array}{c}-.40 \\
(.29) \\
{[-.08]}\end{array}$ & $\begin{array}{c}-.41 \\
(.30) \\
{[-.09]}\end{array}$ & $\begin{array}{c}-.40 \\
(.30) \\
{[-.08]}\end{array}$ & $\begin{array}{c}.19 \\
(.81) \\
{[.02]}\end{array}$ & $\begin{array}{l}.10 \\
(.82) \\
{[.01]}\end{array}$ & $\begin{array}{c}.16 \\
(.81) \\
{[.02]}\end{array}$ \\
\hline $\begin{array}{l}\text { Mother (but not father) is } \\
\text { Immigrant }\end{array}$ & $\begin{array}{c}.16 \\
(.17) \\
{[.04]}\end{array}$ & $\begin{array}{c}.17 \\
(.18) \\
{[.04]}\end{array}$ & $\begin{array}{c}.16 \\
(.18) \\
{[.04]}\end{array}$ & $\begin{array}{c}.15 \\
(.48) \\
{[.02]}\end{array}$ & $\begin{array}{c}.19 \\
(.50) \\
{[.02]}\end{array}$ & $\begin{array}{c}.17 \\
(.50) \\
{[.02]}\end{array}$ \\
\hline Both Parents are Immigrants & $\begin{array}{l}.22 * * \\
(.09) \\
{[.05]}\end{array}$ & $\begin{array}{l}.23 * * \\
(.09) \\
{[.05]}\end{array}$ & $\begin{array}{l}.22 * * \\
(.10) \\
{[.05]}\end{array}$ & $\begin{array}{c}.32 \\
(.20) \\
{[.05]}\end{array}$ & $\begin{array}{l}.35^{*} \\
(.19) \\
{[.05]}\end{array}$ & $\begin{array}{l}.34^{*} \\
(.20) \\
{[.05]}\end{array}$ \\
\hline $\mathrm{N}$ & 1593 & 1593 & 1593 & 775 & 798 & 798 \\
\hline Pseudo $\mathrm{R}^{2}$ & .08 & .08 & .08 & .15 & .15 & .16 \\
\hline
\end{tabular}

Notes:

Ten observations were lost due to collinearity.

Sample sizes precluded using severe infant health condition as the measure of poor child health when estimating insurance loss among children whose births were covered by private insurance.

$* * *$ significant at $1 \%$ level; ** significant at $5 \%$ level; * significant at $10 \%$ level 


\begin{tabular}{cc}
$\begin{array}{c}\text { Mother Had Public Insurance at } \\
\text { Baseline }\end{array}$ & $\begin{array}{c}\text { Mother Had Private Insurance } \\
\text { at Baseline }\end{array}$ \\
\hline Coefficient & Coefficient \\
(Standard Error) & (Standard Error) \\
[Marginal Effect] & [Marginal Effect] \\
\hline
\end{tabular}

Severe Infant Health

$-.01$

(.18)

$[-.00]$
$-.44$

(.36)

[-.06]

Low Birth Weight

.12

(.09)

$-.15$

[.05]

(.21)

$[-.02]$

Any Infant Health Condition

.05

$(.09)$

$-.13$

$(.11)$

[.02]

[-.02]

Male Child

-.09
$(.07)$
$[-.03]$

$-.09$

(.07)

$-.10$

(.07)

$[-.03]$

$[-.04]$

$.18^{*}$

(.10)

[.03]

$.18 *$

(.10)

[.03]

$.18^{*}$

(.10)

[.03]

Maternal Physical Health

$-.18^{*}$

$-.19 *$

$-.19 *$

.11

(.14)

(.11)

[-.07]

(.11)

$[-.07]$

[-.07]

[.02]

.10

.09

(.14)

(.15)

[.02]

[.02]

Maternal History of Mental

Illness

$.23^{* *}$

$.22 * *$

$.23 * *$

(.10)

[.09]

$-.18$

(.32)

[.10)

[-.03]

$-.17$

$-.18$

[.09]

[.08]

(.31)

(.32)

[-.03]

[-.03]

Father's Self-Reported

Suboptimal Health

.01

(.09)

[.00]

.01

(.09)

.01

(.09)

[.00]

$.29 * * *$

(.11)

[.06]

$.28 * * *$

(.10)

[.06]

$.28 * * *$

[.00]

(.10)

[.06]

Father's Depression score (CES-D)

$\begin{array}{ll}-.01 & -.01\end{array}$

(.01)

(.01)

$-.01$

(.01)

$-.01$

(.05)

[-.00]

$-.01$

(.05)

[-.00]

$-.01$

[-.00]

(.05)

[-.00]

$-.11 *$

(.06)

$-.40 * * *$

$-.39 * *$

$-.40 * * *$

Father had Health In
from Last Employer

$-.10 *$

$-.10 *$

[-.04]

(.14)

(.14)

(.14)

[-.04]

[-.04]

[-.08]

[-.08]

[-.08]

Cohabiting at Baseline

$\begin{array}{ll}.12 & .12 \\ (.14) & (.14) \\ {[.04]} & {[.04]}\end{array}$

.12

(.14)

$.43 * *$

$.43 * *$

$.43 * *$

[.04]

(.20)

(.20)

(.20)

[.09]

[.09]

[.09]

Continued on next page 


\begin{tabular}{cc}
$\begin{array}{c}\text { Mother Had Public Insurance at } \\
\text { Baseline }\end{array}$ & $\begin{array}{c}\text { Mother Had Private Insurance } \\
\text { at Baseline }\end{array}$ \\
\hline Coefficient & Coefficient \\
(Standard Error) & (Standard Error) \\
[Marginal Effect] & [Marginal Effect] \\
\hline
\end{tabular}

Not Cohabiting

(.16)

.02

.02

.11

(.16)

(.29)

.11

.12

[.01]

[.01]

[.01]

[.02]

(.30)

(.29)

[.02]

[.02]

Mother Knew Father at Least

$-.02$

$-.02$

$-.02$

.20

.19

.20

(.08)

(.08)

(.08)

(.20)

(.19)

(.19)

[-.01]

[-.01]

[.03]

[.03]

[.03]

Parents Have Other Children

$-.05$

$-.05$

$-.05$

$-.16$

$-.16$

$-.16$

(.08)

(.08)

(.08)

(.20)

(.20)

(.20)

$[-.02]$

[-.02]

[-.02]

[-.03]

[-.03]

[-.03]

Mother has Children with

$-.16^{*}$

$-.16^{*}$

$-.16^{*}$

$-.15$

$-.15$

$-.15$

(.08)

(.09)

(.27)

(.27)

(.27)

[-.06]

[-.06]

[-.06]

[-.03]

[-.03]

[-.03]

Father has Children with

Other Partner

$-.13^{*}$

$-.14 *$

$-.13^{*}$

$-.08$

$-.07$

$-.08$

(.07)

(.08)

(.16)

(.16)

(.16)

[-.05]

[-.05]

[-.05]

[-.01]

[-.01]

[-.01]

Father Visited in Hospital

.12

(.10)

.11

.12

.06

.07

.07

[.04]

(.10)

(.10)

(.24)

(.24)

(.24)

[.04]

[.01]

[.01]

[.01]

Mother's Age

$$
.04
$$

(.05)

$$
.04
$$

.04

$-.04$

$-.05$

$-.04$

[.01]

(.05)

(.05)

(.14)

(.14)

(.14)

[.01]

[-.01]

[-.01]

[-.01]

Mother's Age Squared

-.00
$(.00)$
$[-.00]$

$-.00$

$-.00$

(.00)

.00

(.00)

.00

.00

(.00)

[-.00]

[.00]

(.00)

(.00)

Mother is High School

$-.17 * *$

(.08)

$-.17 * *$

$-.17 * *$

$-.02$

[.00]

[.00]

Graduate

[-.06]

(.08)

(.22)

$-.02$

$-.03$

(.08)

[-.06]

(.23)

(.22)

Mother has Some College But

$-.07$

(.13)

$-.07$

(.13)

$-.07$

[-.00]

[-.00]

[-.01]

[-.03]

[-.02]

$(.13)$
$[-.03]$

-.37
$(.26)$
$[-.06]$

$-.36$

$-.37$

(.25)

(.25)

[-.06]

[-.06]

Continued on next page 


\begin{tabular}{|c|c|c|c|c|c|c|}
\hline \multirow[b]{2}{*}{ Mother is College Graduate } & \multicolumn{3}{|c|}{$\begin{array}{c}\text { Mother Had Public Insurance at } \\
\text { Baseline } \\
\text { Coefficient } \\
\text { (Standard Error) } \\
{[\text { Marginal Effect }]} \\
\end{array}$} & \multicolumn{3}{|c|}{$\begin{array}{c}\text { Mother Had Private Insurance } \\
\text { at Baseline } \\
\text { Coefficient } \\
\text { (Standard Error) } \\
\text { [Marginal Effect] } \\
\end{array}$} \\
\hline & $\begin{array}{c}-.79 * * * \\
(.28) \\
{[-.23]}\end{array}$ & $\begin{array}{c}-.79 * * * \\
(.28) \\
{[-.23]}\end{array}$ & $\begin{array}{c}-.80 * * * \\
(.28) \\
{[-.24]}\end{array}$ & $\begin{array}{c}-.63 * * \\
(.25) \\
{[-.09]}\end{array}$ & $\begin{array}{c}-.62 * * \\
(.26) \\
{[-.09]}\end{array}$ & $\begin{array}{c}-.63 * * \\
(.25) \\
{[-.09]}\end{array}$ \\
\hline $\begin{array}{l}\text { Mother Worked in Past } 2 \\
\text { years }\end{array}$ & $\begin{array}{c}.07 \\
(.10) \\
{[.03]}\end{array}$ & $\begin{array}{l}.08 \\
(.10) \\
{[.03]}\end{array}$ & $\begin{array}{c}.08 \\
(.10) \\
{[.03]}\end{array}$ & $\begin{array}{l}-.13 \\
(.17) \\
{[-.02]}\end{array}$ & $\begin{array}{l}-.12 \\
(.18) \\
{[-.02]}\end{array}$ & $\begin{array}{c}-.12 \\
(.18) \\
{[-.02]}\end{array}$ \\
\hline Mother Non-Hispanic Black & $\begin{array}{l}-.10 \\
(.10) \\
{[-.04]}\end{array}$ & $\begin{array}{l}-.10 \\
(.10) \\
{[-.04]}\end{array}$ & $\begin{array}{l}-.10 \\
(.10) \\
{[-.04]}\end{array}$ & $\begin{array}{l}-.16 \\
(.15) \\
{[-.03]}\end{array}$ & $\begin{array}{l}-.17 \\
(.15) \\
{[-.03]}\end{array}$ & $\begin{array}{l}-.17 \\
(.15) \\
{[-.03]}\end{array}$ \\
\hline Mother Hispanic & $\begin{array}{l}.28 * * \\
(.12) \\
{[.11]}\end{array}$ & $\begin{array}{l}.29 * * \\
(.13) \\
{[.11]}\end{array}$ & $\begin{array}{l}.28 * * \\
(.13) \\
{[.11]}\end{array}$ & $\begin{array}{l}.28 \\
(.19) \\
{[.06]}\end{array}$ & $\begin{array}{l}.28 \\
(.19) \\
{[.05]}\end{array}$ & $\begin{array}{l}.28 \\
(.20) \\
{[.06]}\end{array}$ \\
\hline Mother Other Race/Ethnicity & $\begin{array}{c}-.25 \\
(.20) \\
{[-.09]}\end{array}$ & $\begin{array}{l}-.24 \\
(.20) \\
{[-.09]}\end{array}$ & $\begin{array}{c}-.24 \\
(.20) \\
{[-.09]}\end{array}$ & $\begin{array}{l}-.35 \\
(.32) \\
{[-.05]}\end{array}$ & $\begin{array}{l}-.35 \\
(.30) \\
{[-.05]}\end{array}$ & $\begin{array}{c}-.33 \\
(.30) \\
{[-.05]}\end{array}$ \\
\hline $\begin{array}{l}\text { Number of Previous } \\
\text { Pregnancies }\end{array}$ & $\begin{array}{c}-.07 \\
(.08) \\
{[-.03]}\end{array}$ & $\begin{array}{c}-.07 \\
(.09) \\
{[-.02]}\end{array}$ & $\begin{array}{l}-.07 \\
(.09) \\
{[-.02]}\end{array}$ & $\begin{array}{l}.11 \\
(.17) \\
{[.02]}\end{array}$ & $\begin{array}{l}.11 \\
(.17) \\
{[.02]}\end{array}$ & $\begin{array}{l}.11 \\
(.17) \\
{[.02]}\end{array}$ \\
\hline $\begin{array}{l}\text { Age Difference in Years } \\
\text { (Father Minus Mother) }\end{array}$ & $\begin{array}{l}.01 * \\
(.01) \\
{[.00]}\end{array}$ & $\begin{array}{l}.01^{*} \\
(.01) \\
{[.00]}\end{array}$ & $\begin{array}{l}.01 * \\
(.01) \\
{[.00]}\end{array}$ & $\begin{array}{l}-.01 \\
(.01) \\
{[-.00]}\end{array}$ & $\begin{array}{l}-.02 \\
(.01) \\
{[-.00]}\end{array}$ & $\begin{array}{c}-.02 \\
(.01) \\
{[-.00]}\end{array}$ \\
\hline $\begin{array}{l}\text { Father Different } \\
\text { Race/Ethnicity Than Mother }\end{array}$ & $\begin{array}{l}-.00 \\
(.07) \\
{[-.00]}\end{array}$ & $\begin{array}{l}.00 \\
(.07) \\
{[.00]}\end{array}$ & $\begin{array}{l}-.00 \\
(.07) \\
{[-.00]}\end{array}$ & $\begin{array}{l}.09 \\
(.18) \\
{[.02]}\end{array}$ & $\begin{array}{l}.08 \\
(.19) \\
{[.01]}\end{array}$ & $\begin{array}{l}.08 \\
(.19) \\
{[.02]}\end{array}$ \\
\hline $\begin{array}{l}\text { Father Less Educated Than } \\
\text { Mother }\end{array}$ & $\begin{array}{l}.18 * * \\
(.08) \\
{[.07]}\end{array}$ & $\begin{array}{l}.17 * * \\
(.08) \\
{[.07]}\end{array}$ & $\begin{array}{l}.18 * * \\
(.08) \\
{[.07]}\end{array}$ & $\begin{array}{l}.28 \\
(.21) \\
{[.05]}\end{array}$ & $\begin{array}{l}.28 \\
(.21) \\
{[.05]}\end{array}$ & $\begin{array}{l}.28 \\
(.21) \\
{[.05]}\end{array}$ \\
\hline Father Served in Military & $\begin{array}{c}-.08 \\
(.17) \\
{[-.03]}\end{array}$ & $\begin{array}{c}-.08 \\
(.16) \\
{[-.03]}\end{array}$ & $\begin{array}{c}-.08 \\
(.16) \\
{[-.03]}\end{array}$ & $\begin{array}{c}.09 \\
(.15) \\
{[.02]} \\
\end{array}$ & $\begin{array}{c}.09 \\
(.15) \\
{[.02]} \\
\end{array}$ & $\begin{array}{c}.09 \\
(.16) \\
{[.02]} \\
\end{array}$ \\
\hline
\end{tabular}




\begin{tabular}{|c|c|c|c|c|c|c|}
\hline \multirow[b]{2}{*}{ Father Employed at Baseline } & \multicolumn{3}{|c|}{$\begin{array}{c}\text { Mother Had Public Insurance at } \\
\text { Baseline } \\
\text { Coefficient } \\
\text { (Standard Error) } \\
\text { [Marginal Effect] } \\
\end{array}$} & \multicolumn{3}{|c|}{$\begin{array}{c}\text { Mother Had Private Insurance } \\
\text { at Baseline } \\
\text { Coefficient } \\
\text { (Standard Error) } \\
\text { [Marginal Effect } \\
\end{array}$} \\
\hline & $\begin{array}{c}.02 \\
(.07) \\
{[.01]}\end{array}$ & $\begin{array}{c}.02 \\
(.07) \\
{[.01]}\end{array}$ & $\begin{array}{c}.02 \\
(.07) \\
{[.01]}\end{array}$ & $\begin{array}{c}-.17 \\
(.16) \\
{[-.03]}\end{array}$ & $\begin{array}{c}-.18 \\
(.16) \\
{[-.04]}\end{array}$ & $\begin{array}{c}-.17 \\
(.16) \\
{[-.03]}\end{array}$ \\
\hline $\begin{array}{l}\text { Father Did Not Complete } \\
\text { Baseline Interview }\end{array}$ & $\begin{array}{l}-.09 \\
(.12) \\
{[-.03]}\end{array}$ & $\begin{array}{c}-.08 \\
(.12) \\
{[-.03]}\end{array}$ & $\begin{array}{c}-.09 \\
(.12) \\
{[-.03]}\end{array}$ & $\begin{array}{c}-.08 \\
(.22) \\
{[-.01]}\end{array}$ & $\begin{array}{c}-.08 \\
(.22) \\
{[-.01]}\end{array}$ & $\begin{array}{c}-.10 \\
(.22) \\
{[-.02]}\end{array}$ \\
\hline $\begin{array}{l}\% \text { Below Poverty in Mother's } \\
\text { Census Tract }\end{array}$ & $\begin{array}{c}-.53 * * \\
(.25) \\
{[-.20]}\end{array}$ & $\begin{array}{c}-.53 * * \\
(.24) \\
{[-.20]}\end{array}$ & $\begin{array}{c}-.53 * * \\
(.25) \\
{[-.20]}\end{array}$ & $\begin{array}{l}.86^{*} \\
(.48) \\
{[.15]}\end{array}$ & $\begin{array}{l}.84 * \\
(.47) \\
{[.15]}\end{array}$ & $\begin{array}{l}.84 * \\
(.47) \\
{[.15]}\end{array}$ \\
\hline $\begin{array}{l}\text { Mother (but not father) is } \\
\text { Immigrant }\end{array}$ & $\begin{array}{l}.40 * * \\
(.19) \\
{[.15]}\end{array}$ & $\begin{array}{l}.40 * * \\
(.19) \\
{[.16]}\end{array}$ & $\begin{array}{l}.40 * * \\
(.18) \\
{[.16]}\end{array}$ & $\begin{array}{c}.29 \\
(.36) \\
{[.06]}\end{array}$ & $\begin{array}{c}.32 \\
(.35) \\
{[.07]}\end{array}$ & $\begin{array}{c}.30 \\
(.35) \\
{[.06]}\end{array}$ \\
\hline Both Parents are Immigrants & $\begin{array}{l}.59 * * \\
(.24) \\
{[.23]}\end{array}$ & $\begin{array}{l}.59 * * \\
(.24) \\
{[.23]}\end{array}$ & $\begin{array}{l}.58 * * \\
(.24) \\
{[.23]}\end{array}$ & $\begin{array}{c}.25 \\
(.23) \\
{[.05]}\end{array}$ & $\begin{array}{c}.26 \\
(.23) \\
{[.05]}\end{array}$ & $\begin{array}{c}.26 \\
(.23) \\
{[.05]}\end{array}$ \\
\hline $\mathrm{N}$ & 1602 & 1602 & 1602 & 801 & 801 & 801 \\
\hline Pseudo $\mathrm{R}^{2}$ & .12 & .12 & .12 & .16 & .16 & .16 \\
\hline
\end{tabular}

